\title{
Steam Storage Systems for Flexible Biomass CHP plants - Evaluation and Initial Model Based Calculation
}

\author{
Authors \\ Matthias Stark ${ }^{a}$, Fosca Conti ${ }^{b}$, Abdessamad Saidic $^{c}$, Wilfried Zörner ${ }^{d}$, Rick Greenough ${ }^{\mathrm{e}}$ \\ acd Institute of new Energy Systems, Technische Hochschule Ingolstadt, Esplanade 10, 85049 Ingolstadt, Ger- \\ many \\ ${ }^{\mathrm{b}}$ Department of Chemical Sciences, University of Padova, via Marzolo 1, 35141 Padova, Italy \\ e Institute of Energy and Sustainable Development, De Montfort University, The Gateway Leicester, LE1 9BH \\ UK \\ a E-Mail, matthias.stark@thi.de, tel.: +49(0)841 93486405
}

\begin{abstract}
Within the present study a novel concept for the demand-oriented power generation of a solid-biomass fueled combined heat and power (CHP) plant is investigated. The integration of a novel steam storage system into the plants process enables a decoupling of the steam (boiler) and the power generation (steam turbine). By buffering the steam, the power output of the turbine can be adjusted without changing the rated thermal capacity of the plant. The storage system consist of combination of steam accumulator and concrete storage. An initial model based simulation study is performed to identify the fundamental behavior of this system, integrated in a biomass CHP plant. The operation principle has proved their technical feasibility and seems to be applicable at a commercial scale. According to the modelling results flexible short term power generation in a time range from fifteen minutes to several hours is applicable. A load-range of almost the plant's rated capacity can be achieved. The properties of the proposed concept are competitive to available energy storage systems.
\end{abstract}

\section{Keywords}

CHP, solid biomass, steam storage, high temperature storage, flexible power generation

\section{Text of the contribution}

\section{Introduction}

\subsection{Background}

The rising amount of renewable energy generation with variable and non-dispatchable production capacity, such as wind and photovoltaic power plants, requires measures to maintain balance between supply and demand for the electricity grid [1]. Due to the extensive installation of renewable generators within the last few years, these challenges apply particularly to the German electricity grid. To face these challenges, three main approaches can be used: (1) The application of demand-side management with initiatives and technologies that encourage consumers to optimize their energy consumption; (2) the employment of energy storage technologies to decouple variable supply from variable demand [1]; (3) the utilization of flexible operating power plants to adjust the power generation according to the grid demand [2].

In this context, the ability to generate electricity independently from weather conditions represents a major competitive advantage of bioenergy plants compared to other renewable energy technologies. Several biogas plants are already generating electricity according to the grid demand [3]. However, due to the slow load change dynamics, a flexible operation of solid biomass-fueled combined heat and power (CHP) plants has not been applied yet [4]. 
The research issue, discussed in the present paper, is focused on biomass CHP plants with steam cycles. These plants are characterized by three main processes: The conversion of the heat released from combustion of the wood chips in a boiler to raise steam at high pressure and temperature (a), the expansion of the steam through a turbine for generation of electrical power (b) and the condensation of the exhaust steam from the turbine in a heat exchanger (c), which is subsequently returned to the boiler concluding the cycle. At present, the majority of these plants are used for in baseload power generation.

\subsection{Research approach}

An approach to adapt biomass CHP plants to demand-oriented operation by integrating a steam storage system into the steam cycle is presented by Stark et al. [5]. The g decoupling of steam generation (combustion and steam generator) and energetic steam utilization (turbine) enables an adjustable power production by managing the charge of the storage system (Figure 1).

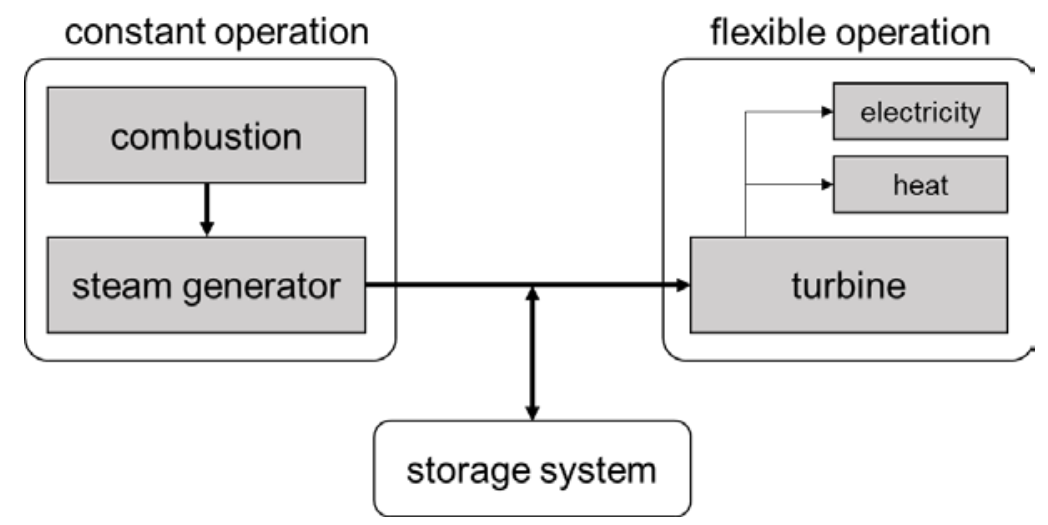

Figure 1: Storage approach according to Stark et al. [5].

A variety of different technologies and systems are available. Especially for the application in concentrated solar thermal plants, the storage of steam has received a lot of attention in the last decade. Several new or improved concepts for steam storage like steam accumulators, molten-salt or concrete storage systems have been developed [6]. As a lot of research for the steam storage in this field of technology were done, the utilization for biomass CHP plants is a novel approach due to the individual operation parameters and boundaries [5]. Stark et al. [7] evaluated the available storage concepts and identified the combination of a steam accumulator (SA) with a concrete storage (CS) as the most promising option for flexible biomass CHP plants. Since the 1930s SA are used for the thermal storage of process steam for several industrial sectors, such as the food [8,9] and pharma industry $[10,11]$. The novelty in this paper does not lie in the SA itself, but in the application of this established technology to support the electricity grid in an energy system that incorporates CS and biomass CHP. A major challenge for the SA technology is the limitation to saturated steam during discharge. Even though the most typical industrial applications are operated with saturated steam, the utilization in steam turbines requires superheated steam. Bai and Xu [12] investigated the effect of a CS to enable a superheating of the saturated discharge steam from SA.

A novel aspect of the present research is the application of the SA combined with the CS and especially with steam turbines. Unlike the operation of a conventional steam turbine, with fixed input pressure and nearly constant massflow rate, the use of an SA led to the generation of steam with a sliding pressure. To investigate the fundamental behavior of the selected system, an initial simulation study is performed. Even though, the individual components - like steam turbine or steam accumulator - represent commercially applied technologies, the system as a combination has not been investigated before. Especially, the interdependencies between SA and steam turbine will be of particular interest.

In addition, the initial simulation study is intended to identify the main issues, which are to be considered for further detailed studies. During the simulation runs, the parameters with the strongest impact on the system can be determined.

The impact of the sliding pressure discharge steam on the turbine power generation as well as identification of the storage systems key properties (e.g. storage efficiency, energy density) is of special interest. 


\section{Evaluation of available storage technologies}

In order to define the optimal steam storage system for flexible power generation from biomass CHP plants, power grid demands, storage technologies and combustion system represent the main factors [8-11], which are considered by Stark et al. [5, 7] to identify the 8 most promising storage concepts. The available systems have in common that a latent heat component for the storage of the condensation/evaporation energy and a sensible heat component for the superheating and sub-cooling is utilized. For the latent heat, water or a chemicals (i.e. $\mathrm{LiNO}_{3}, \mathrm{KNO}_{3}+\mathrm{NaNO}_{3}$ ) with phase-change at suitable temperature and pressure ranges can be used as an energy storage medium. The storage of the sensible heat is achieved via a solid thermal energy store or a molten salt tank system. For the PCM storage, both lithium nitrate $\left(\mathrm{LiNO}_{3}\right)$ as well as sodium and potassium nitrate $\left(\mathrm{KNO}_{3}+\mathrm{NaNO}_{3}\right)$ have appropriate properties for the present application, therefore both materials are considered for the evaluation (Table 1).

Table 1: Selected storage systems.

\begin{tabular}{|c|c|c|}
\hline Acronym & Latent parts & Sensible parts \\
\hline \hline SA+2T & Steam accumulator & 2 tank molten salt storage \\
\hline $\mathrm{SA}+\mathrm{C}$ & Steam accumulator & Solid thermal concrete storage \\
\hline $\mathrm{PL}+2 \mathrm{~T}$ & $\mathrm{PCM}\left(\mathrm{LiNO}_{3}\right)$ & 2tank molten salt storage \\
\hline $\mathrm{PL}+3 \mathrm{~T}$ & $\mathrm{PCM}\left(\mathrm{LiNO}_{3}\right)$ & 3 tank molten salt storage \\
\hline $\mathrm{PL}+2 \mathrm{C}$ & $\mathrm{PCM}\left(\mathrm{LiNO}_{3}\right)$ & 2 solid thermal concrete storages \\
\hline $\mathrm{PK}+2 \mathrm{~T}$ & $\mathrm{PCM}\left(\mathrm{KNO}_{3}+\mathrm{NaOH}_{3}\right)$ & 2 tank molten salt storage \\
\hline $\mathrm{PK}+3 \mathrm{~T}$ & $\mathrm{PCM}\left(\mathrm{KNO}_{3}+\mathrm{NaOH}_{3}\right)$ & 3 tank molten salt storage \\
\hline $\mathrm{PK}+2 \mathrm{C}$ & $\mathrm{PCM}\left(\mathrm{KNO}_{3}+\mathrm{NaOH}_{3}\right)$ & 2 solid thermal concrete storages \\
\hline
\end{tabular}

To select the most suitable steam storage system for biomass combustion plants, the adapted Analytic Hierarchy Process (AHP), an established assessment method recommended by Billig et al. [4] has been applied. It consists of the following six main steps: Description of the problem, definition of criteria and sub-criteria, prioritization of the criteria, assignment of parameters to the criteria, development of an assessment scheme and evaluation of the resulting concepts.

\subsection{Description of the problem and definition of the criteria}

For an expedient description of the problem according to the AHP the storage system should be considered not merely as a stand-alone component but also in the context of the total system. The biomass CHP plant is upgraded to a flexible plant by implementing the storage system. Therefore, the aim is to identify the optimum concept in terms of a flexible plants operation.

For the next step of the AHP, assessable criteria are defined. In Figure 2 the main criteria and corresponding sub-criteria are shown. The criteria explained in more detail by Stark et al. [7].

\subsection{Prioritization of the criteria}

Recently Stark et al. [5] calculated a priority median of the criteria using the established Delphi method with a panel of experts with professional background in research and development, electricity trading, plant operation, plant design and further sectors. The results are shown in Figure 2. The Delphi survey shows that the cost criterion covers $31 \%$ of the priority, while the performance criterion covers $16 \%$, efficiency covers $11 \%$ and the application area criterion covers $20 \%$. The remaining $22 \%$ in the prioritization of the criteria is attributed to the criterion process synergies by the experts, answering the questionnaires of the Delphi survey. 


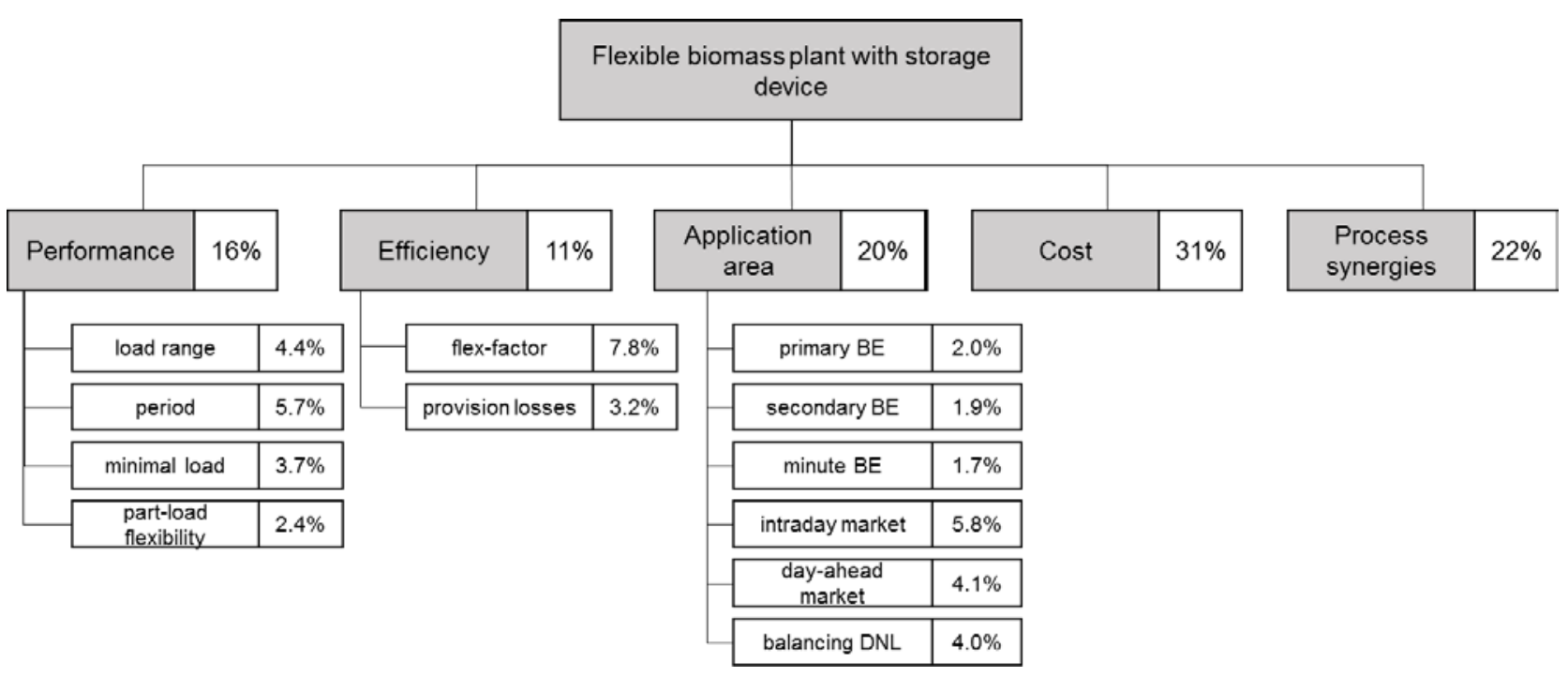

Figure 2: Criterion and sub-criterion with priority median.

\subsection{Assignment of Parameters to the Criteria \& Development of an Assessment Scheme}

To evaluate the storage systems, each concept is rated according to a degree of fulfilment (DoF) on a linear scale from 0 to 4 for each criterion (Table 2). An assessment matrix is created, where a DoF is assigned to each system for each criterion. As an example, the combination of a SA with two-tank molten salt (SA-2T) with a load range of $92 \%$ is rated with two points in this category (Table 2).

Table 2: DoF.

\begin{tabular}{|c|c|c|c|c|c|c|c|c|c|}
\hline DoF & $\begin{array}{c}\text { Load range } \\
(\%)\end{array}$ & $\begin{array}{c}\text { Period } \\
(\mathrm{h})\end{array}$ & $\begin{array}{c}\text { Minimum } \\
\text { Load } \\
(\%)\end{array}$ & $\begin{array}{c}\text { Part-load } \\
\text { flexibility } \\
(-)\end{array}$ & $\begin{array}{c}\text { Flex- } \\
\text { factor } \\
(\%)\end{array}$ & $\begin{array}{c}\text { Provision } \\
\text { losses } \\
(-)\end{array}$ & $\begin{array}{c}\text { Markets } \\
(-)\end{array}$ & $\begin{array}{c}\text { Process } \\
\text { synergies } \\
(-)\end{array}$ & $\begin{array}{c}\text { Costs } \\
(\mathrm{k} €)\end{array}$ \\
\hline \hline $\mathbf{4}$ & $>105 \%$ & $>3$ & $0 \%$ & $\begin{array}{c}\text { infinitely } \\
\text { variable }\end{array}$ & $>90 \%$ & high & possible & 0 & $<1,000$ \\
\hline $\mathbf{3}$ & $100-105 \%$ & $2-3$ & $0-25 \%$ & & $90-85 \%$ & & & 1 & $1,000-1,500$ \\
\hline $\mathbf{2}$ & $90-100 \%$ & $1-2$ & $25-50 \%$ & $>4$ & $84-80 \%$ & average & $\begin{array}{c}\text { possible } \\
\text { with effort }\end{array}$ & 2 & $1,500-2,000$ \\
\hline $\mathbf{1}$ & $80-90 \%$ & $0.5-1$ & $50-75 \%$ & & $80-70 \%$ & & & 3 & $2,000-2,500$ \\
\hline $\mathbf{0}$ & $<80 \%$ & $<0.5$ & $75-100 \%$ & 1 & $<70 \%$ & low & $\begin{array}{c}\text { not } \\
\text { possible }\end{array}$ & 4 \\
\hline
\end{tabular}

\subsection{Evaluation of the Resulting Concepts}

The total utility value of each system is calculated according to Pahl et al. [13]. Each value of the DoF is multiplied with the corresponding priority from Figure 3. For example the SA-2T system has a DoF of 2 for the criterion load range, which has a priority of $4.4 \%$. Both values are multiplied. Adding all the results of a system results in the utility value. As the maximum value is 4 , the results normalized to this maximum (Figure 3 ). 


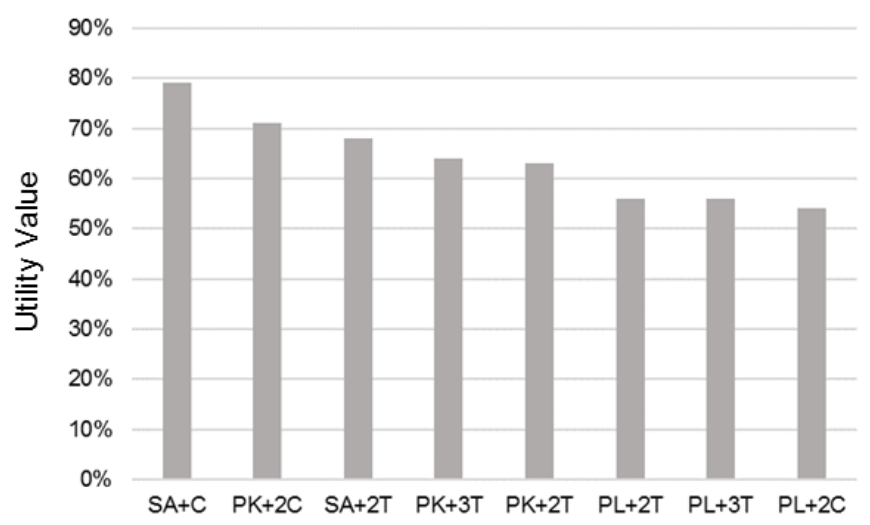

Figure 3: Results of the utility value analysis.

The highest utility value (79\%) is obtained for the storage system consisting of a SA combined with a concrete storage (SA+CS). With only $54 \%$, the PL+2CS system shows the lowest rating. Despite the lower performance and efficiency of the SA+CS concept compared to the PCM concepts, low investment costs and the advantage of a short time reaction to a market signal dominate overall.

\section{Methodology of the initial simulation}

The main aim of the research is to derive a model that will assist designers to optimize performance of biomassbased energy systems. For this aim an initial modelling and simulation exercise was performed. Based on the results a more detailed model will be created and validated in future. Following steps are performed in this research.

- Development of a simplified Matlab/Simulink model of the storage system

- Calculation of exemplary charge and discharge procedures

- Investigation of the fundamental system behavior

- Derivation of main research issues for the subsequent, more detailed simulations

For the present system view, the fundamental performance of the main components is more important than the detailed physical behaviour. The fluid mechanics and thermal influence of pipes, fittings, valves and measurement equipment are not considered. Also the effect of thermal losses and dynamics of the charge and discharge valves are not covered. The aim of this initial simulation is to identify the interdependencies between the components, especially between SA and ST, on a system level. Therefore the errors caused by this simplification are not considered been further discussed. However, a detailed error analyses is required in the further steps of this research.

\subsection{Model Framework}

The storage system consists of the main components SA, CS and storage turbine (ST) as shown in Figure 4. 
steam storage system

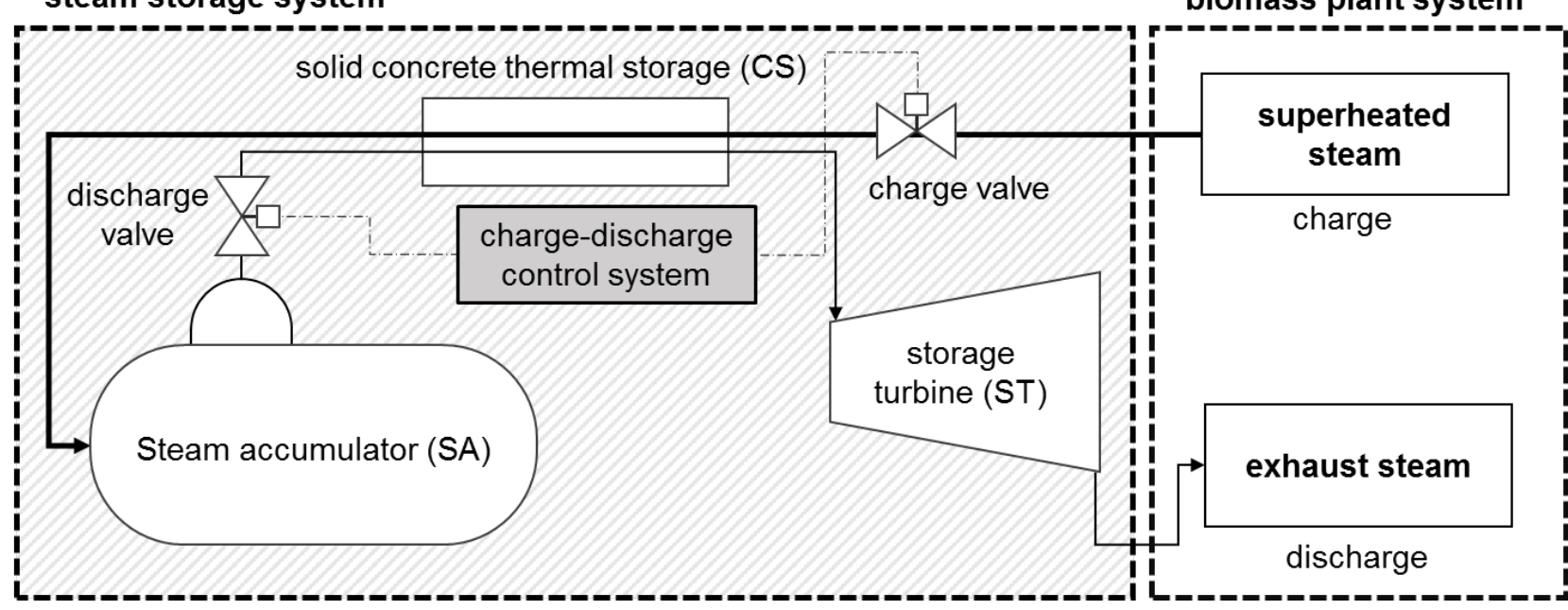

Figure 4: Storage concepts.

Figure 5 illustrates the interconnection between the storage system and the biomass CHP plant. The charge line is set between the steam boiler and the plant's turbine, wherefore a share of the live-steam can be fed into the storage system. During discharge, the exhaust steam from the storage turbine is relaxed to a lower pressure level, depending on the further utilization. It can be utilized in the heat condenser for external heat supply or feed into CHP plants condenser.

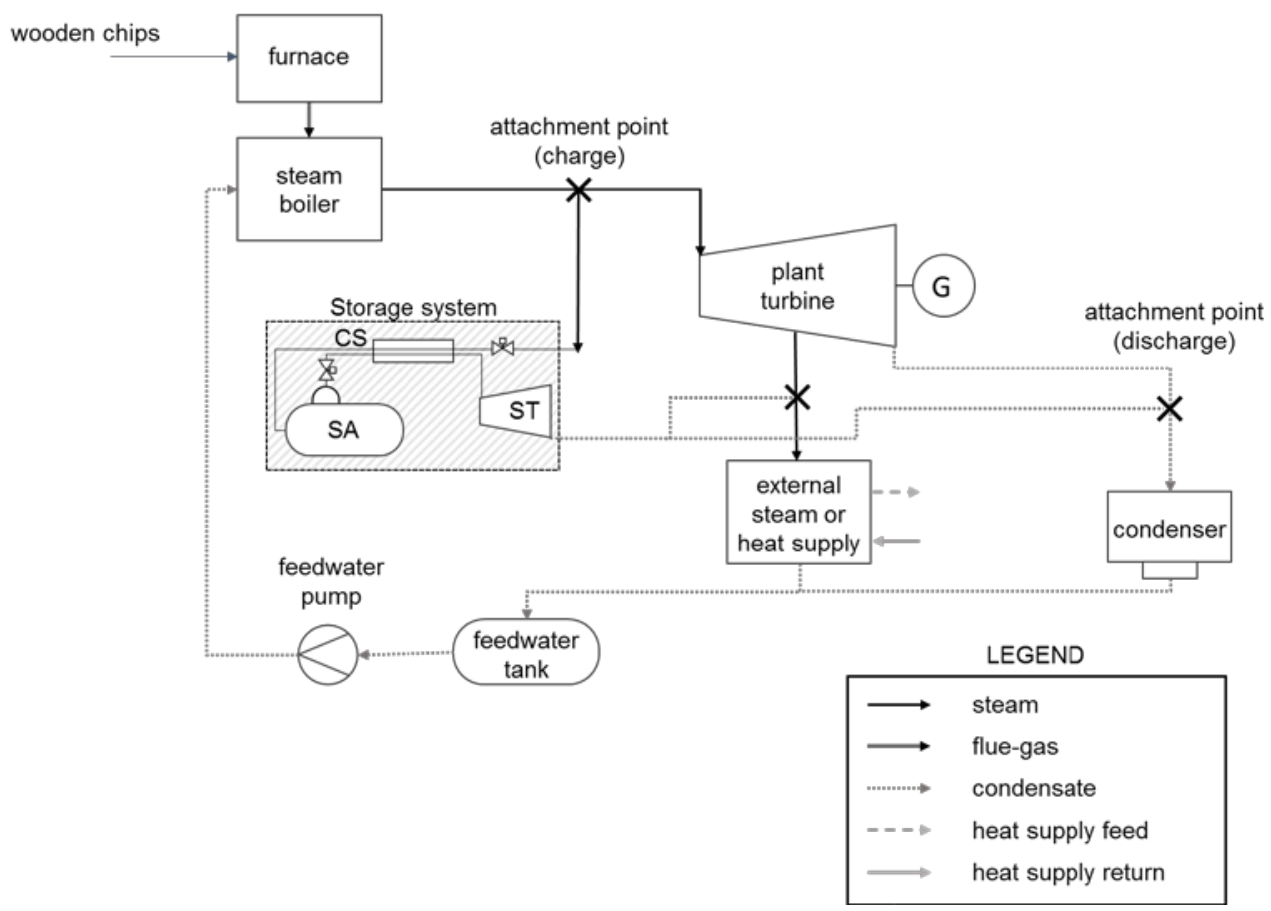

Figure 5: Connection of the storage system into the biomass CHP plant.

In this scheme the storage turbine (ST), which is operated in addition to the plant turbine, is considered to be part of the energy storage system. Both, ST and plant turbine are steam turbines.

\subsection{Steam accumulator (SA)}

The SA represents an established storage technology. Steam accumulators store sensible heat as liquid water. The operation principle of the SA technology is described by Steinmann \& Eck [14].

The modelling of the SA is based on the equilibrium model of Stevanovic et al. [15]. This model is selected because of its high accuracy, the ability to calculate the dynamic behaviour of the SA and the scalability to suitable storage volumes. Biglia et al. [16] proposed this model formulation as a suitable tool to verify the 
operation conditions of a SA. It has also been applied in several studies in which a SA is integrated into processes of the food and pharmaceutical industries [8-11].

The equilibrium model considers the content of the SA as a steam/liquid mixture. Inside of the SA, the mass $M$, the pressure $p$ and the enthalpy $h$ are calculated. Input and output massflow $\left(m ;{ }_{n, i n}, m ;{ }_{n, o u t}\right)$ as well the enthalpy of the input stream $h_{n}$, are considered for both liquids (1) and vapor (2) (Figure 6).

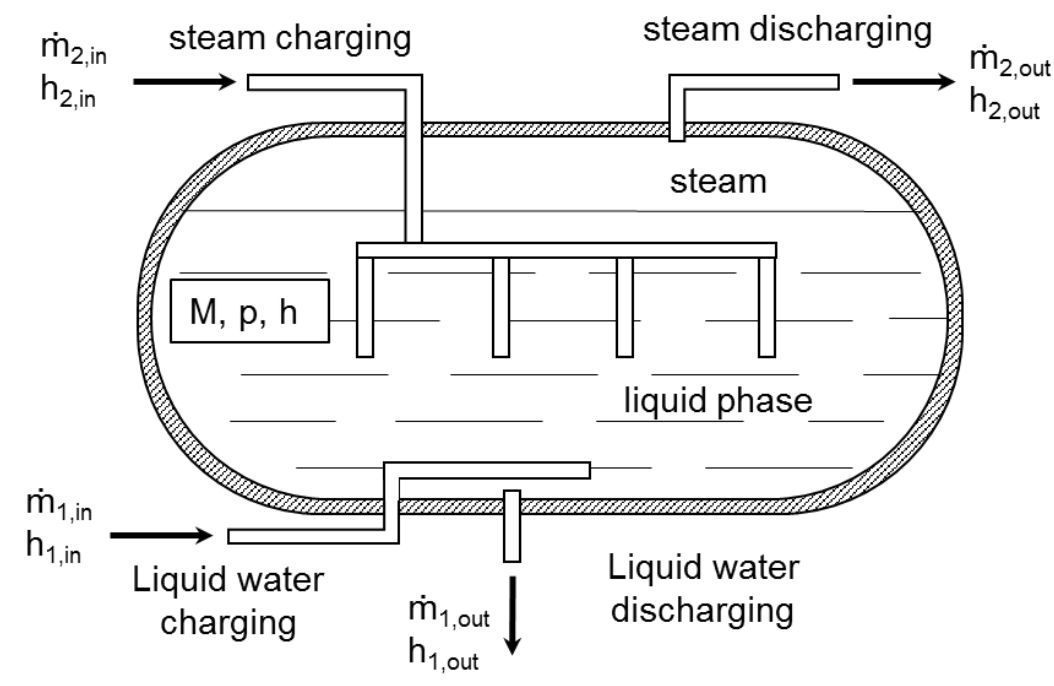

Figure 6: Steam accumulator according to Stevanovic et al. [15].

The equilibrium model consist of a set of equations (1-3), based on the mass, energy and volume balance.

$$
\begin{array}{lr}
\frac{d M}{d t}=\dot{m}_{1 B}+\dot{m}_{2 B} & \text { Equation 1 } \\
\frac{d H}{d t}=(\dot{m} h)_{1 B}+(\dot{m} h)_{2 B}+V \frac{d p}{d t} & \text { Equation 2 }
\end{array}
$$

The boundaries in equation 1 and 2 are calculated for the massflow rates as $\dot{m}_{n, B}=\dot{m}_{n, \text { in }}-\dot{m}_{n, \text { out }}$ and consequently for the energy flow rates as $(\dot{m} h)_{n, B}=(\dot{m} h)_{n, \text { in }}-(\dot{m} h)_{n, \text { out }}$.

$$
\frac{d p}{d t}=\frac{(\dot{m} h)_{1 B}+(\dot{m} h)_{2 B}+\left(\frac{\frac{r V}{M}}{\vartheta^{\prime \prime}-\vartheta^{\prime}}-h\right)\left(\dot{m}_{1 B}+\dot{m}_{2 B}\right)}{M\left(\frac{d h^{\prime}}{d p}+\frac{\frac{V}{M}-\vartheta^{\prime}}{\vartheta^{\prime \prime}-\vartheta^{\prime}} \frac{d r}{d p}-\frac{r}{\vartheta^{\prime \prime}-\vartheta^{\prime}} \frac{d \vartheta^{\prime}}{d p}-r \frac{\frac{V}{M}-\vartheta^{\prime}}{\left(\vartheta^{\prime \prime}-\vartheta^{\prime}\right)^{2}} \frac{d\left(\vartheta^{\prime \prime}-\vartheta^{\prime}\right)}{d p}\right)-V}
$$

Equation 3

The specific volumes of the saturated liquid $\vartheta^{\prime}$ and steam $\vartheta^{\prime \prime}$, the latent heat of the phase transition $r$ as well as the liquid enthalpy $h^{\prime}$ are functions of the pressure. The total internal volume of the SA is given $V_{S A}$ as a boundary.

\subsection{Storage turbine (ST)}

To calculate the turbine performance the modelling approach of Sun \& Smith is applied [17]. Their equations can be used to calculate the part-load behaviour and are validated for small scale turbines.

The ST power output is calculated using the fundamental thermodynamic equation $P_{e l}=\eta_{\text {mech }}{ }^{*} \eta_{\text {isen }}{ }^{*} \dot{m}^{\star} \Delta h_{i s}$, including the isentropic enthalpy difference $\Delta h_{\text {is }}$, steam massflow m; , isentropic efficiency $\eta_{\text {is }}$ and mechanical efficiency $\eta_{\text {mech }}$.

Typically, the mechanical efficiency is in the range of 0.97 and 0.99 and is not significantly impacted by partload operation [17], whereas the isentropic efficiency is highly load-dependent. 
The main parameters influencing the efficiency, especially the part load efficiency, of a steam turbine are the type of the turbine (back-pressure or extraction), the turbine dimensions, the maximum electrical performance, the inlet pressure and temperature, the outlet steam pressure and the operating load (part-load conditions) [17].

These parameters are considered for the calculation of $\eta_{i s}$, which represents the main output of the model (Equation 4).

$$
\eta_{i s}=\frac{n * \dot{m}-W_{I N T}}{\dot{m} * \eta_{\text {mech }} * \Delta H_{i s}} \quad \text { Equation } 4
$$

The equations for the slope $n$ (Equation 5) and the intercept $W_{I N T}$ (Equation 6) of the Willan's line are based on the design mass flow (maximum mass flow) $m$; ${ }^{\prime m a x}$ and the model coefficients $a, b$ and $c$. The Willans line is a common approach for the calculation of the part-load behaviour of steam turbines [17].

$$
\begin{array}{ll}
n=\frac{(1+c)}{a} *\left(\Delta H_{i s}-\frac{b}{\dot{m}_{\max }}\right) & \text { Equation } 5 \\
W_{I N T}=\frac{c}{a} *\left(\dot{m}_{\max } * \Delta H_{i s}-b\right) & \text { Equation } 6
\end{array}
$$

The model coefficients $a, b$ and $c$ are calculated by taking the inlet $p_{\text {in }}$ and outlet $p_{\text {out }}$ pressure into account (equation 7-9).

$$
\begin{array}{lr}
a=a_{1}+a_{2} p_{\text {in }}+a_{3} p_{\text {out }} & \text { Equation } 7 \\
b=b_{1}+b_{2} p_{\text {in }}+b_{3} p_{\text {out }} & \text { Equation } 8 \\
c=c_{1}+c_{2} p_{\text {in }}+c_{3} p_{\text {out }} & \text { Equation } 9
\end{array}
$$

The coefficient parameters $a_{x}, b_{x}$ and $c_{x}$, are determined by a regression of commercial turbine data (Table 3 ) for backpressure steam turbines (BPST) and condensing turbines. These coefficients have been adapted to commercial turbines at full-load and part-load operation [17].

Table 3: Steam Turbines Modelling Coefficients for BPST [17]

\begin{tabular}{|l|l|}
\hline & \multicolumn{1}{|c|}{ BPST } \\
\hline $\mathrm{a}_{1}$ & 1.18795366 \\
\hline $\mathrm{a}_{2}$ & -0.00029564 \\
\hline $\mathrm{a}_{3}$ & 0.004647288 \\
\hline $\mathrm{b}_{1}$ & 449.9767142 \\
\hline $\mathrm{b}_{2}$ & 5.67016939 \\
\hline $\mathrm{b}_{3}$ & -11.5045814 \\
\hline $\mathrm{c}_{1}$ & 0.205149333 \\
\hline $\mathrm{c}_{2}$ & -0.000695171 \\
\hline $\mathrm{c}_{3}$ & 0.002844611 \\
\hline
\end{tabular}

\subsection{Solid concrete thermal store (CS)}

The solid concrete thermal store is a bidirectional storage concept, where charge and discharge steam alternately flows through the same heat exchanger. Within the charging process, the superheated live-steam heats up the concrete material. While discharging the SA, the saturated steam is superheated by the stored energy from the CS (Figure 4). For this study, the storage material is assumed to be high temperature concrete. 
For the CS, a constant temperature difference of $-30 \mathrm{~K}$ during charging and a $15 \mathrm{~K}$ during discharging is a simplifying assumption. The subordinate task of the solid concrete thermal storage is the superheating of the steam, to avoid wet steam from entering the turbine and causing erosion and steam coils.

\section{Calculation of the steam storage system}

As mentioned in 2.1, the storage system has to be considered as a part of the whole plant system. To estimate the effect of the integration, two different types of simulation runs are performed:

- Charging process: Live-steam is extracted between steam generation and plant turbine to charge the storage system. The Baseload generation is reduced due to the lower steam massflow fed into the turbine.

- Discharging process: The SA+CS is discharged by releasing steam which is fed into the ST which then generates an additional amount of electricity.

Comparing the performance of the charging and discharging process, the total effect of the flexible biomass $\mathrm{CHP}$ can be evaluated.

For the simulation runs, an average biomass CHP plant is assumed with a rated capacity of $6 \mathrm{MW}$, a livesteam massflow of $6.5 \mathrm{~kg} / \mathrm{s}$, a steam temperature of $480^{\circ} \mathrm{C}$ and a steam pressure of $6.3 \mathrm{MPa}$. A constant heat supply via extraction steam at $0.3 \mathrm{MPa}$ is defined. During baseload operation, the plant is generating $5.97 \mathrm{MW}$. When the steam storage system is charging, a minimum load $P_{\min }$ of $2.46 \mathrm{MW}$ is generated (Table 4), due to the reduced live-steam of $3.5 \mathrm{~kg} / \mathrm{s}$ fed into the plant turbine.

Table 4: Operation parameter of the biomass CHP plant.

\begin{tabular}{|l|c|c|c|c|c|}
\hline $\begin{array}{l}\text { Biomass ‘ } \\
\text { CHP plant }\end{array}$ & $\begin{array}{c}\text { Live-steam } \\
\text { into plant } \\
\text { turbine }\end{array}$ & $\begin{array}{c}\text { Live-steam } \\
\text { into storage } \\
\text { system }\end{array}$ & $\begin{array}{c}\text { Extraction } \\
\text { steam }\end{array}$ & $\begin{array}{c}\text { Turbine } \\
\text { performance }\end{array}$ & Operation \\
\hline Baseload & $6,5 \mathrm{~kg}^{*} \mathrm{~s}^{-1}$ & $0 \mathrm{~kg}^{\star} \mathrm{S}^{-1}$ & $1 \mathrm{~kg}^{\star} \mathrm{s}^{-1}$ & $5.97 \mathrm{MW}$ & $\begin{array}{c}\text { Discharging } \\
\text { Baseload }\end{array}$ \\
\hline $\begin{array}{l}\text { Minimum } \\
\text { Load }\end{array}$ & $3,5 \mathrm{~kg}^{\star} \mathrm{s}^{-1}$ & $3 \mathrm{~kg}^{\star} \mathrm{S}^{-1}$ & $1 \mathrm{~kg}^{\star} \mathrm{s}^{-1}$ & $2.46 \mathrm{MW}$ & Charging \\
\hline
\end{tabular}

The SA is operated between $1 \mathrm{MPa}\left(p_{\min }\right.$, empty storage) and $6 \mathrm{MPa}\left(p_{\max }\right.$, filled storage). At the beginning of the charging process, a live-steam massflow $\dot{m}_{\text {cha }}$ of $3.0 \mathrm{~kg} / \mathrm{s}$ is fed passing the CS into the SA. The charging process stops as soon as the SA reaches the maximum load pressure $p_{\max }$. The simulations of the process are performed for different volumes $V_{S A}$ of the $S A$. At the end of the charging process the state variables of the $\mathrm{SA}(M, p, h)$ are submitted as initial values to the discharging process.

For the discharging process, a defined massflow $\dot{m}_{\text {dis }}$ is extracted from the SA. The saturated steam is superheated by passing the CS and subsequently fed into the ST. The ST generates an additional amount of electricity $P_{S T}$. The discharging process is stopped as soon as the minimum pressure $p_{\min }$ is reached inside the $S A$. According to the variation of the storage volume of the SA for the charging process the discharging process is calculated for various massflows $\dot{m}_{d i s}$ and ST sizes. To enable the integration of the downstream heat condensing cycle, the turbine's back pressure was set at $0.1 \mathrm{MPa}$. As mentioned in Stark et al. [18], the supply electricity on the spot markets required time slices from 15 minutes to several hours. Hence the turbine size is adjusted to discharge the SA in according time slices.

Table 5: Storage turbine dimension

\begin{tabular}{|l|c|c|c|}
\hline Turbine (BPST) & $\dot{m}_{\text {dis }}$ & $\dot{m}_{S T, \max }$ & $P_{S T, \max }$ \\
\hline T1 & $2.5 \mathrm{~kg}^{\star} \mathrm{S}^{-1}$ & $2.5 \mathrm{~kg}^{\star} \mathrm{S}^{-1}$ & $0.80 \mathrm{MW}$ \\
\hline T2 & $4 \mathrm{~kg}^{\star} \mathrm{S}^{-1}$ & $4 \mathrm{~kg}^{\star} \mathrm{S}^{-1}$ & $1.68 \mathrm{MW}$ \\
\hline T3 & $5.5 \mathrm{~kg}^{\star} \mathrm{S}^{-1}$ & $5.5 \mathrm{~kg}^{\star} \mathrm{S}^{-1}$ & $2.56 \mathrm{MW}$ \\
\hline
\end{tabular}




\section{Results and Discussion}

\subsection{Charge operation}

In total, the charging procedures are simulated for SA volumes from $50 \mathrm{~m}^{3}$ to $300 \mathrm{~m}^{3}$, charged with a mass flow of $3.0 \mathrm{~kg}^{\star} \mathrm{s}^{-1}$. The storage charge behavior and steam capacity of the storage types are shown in Figure 7 .

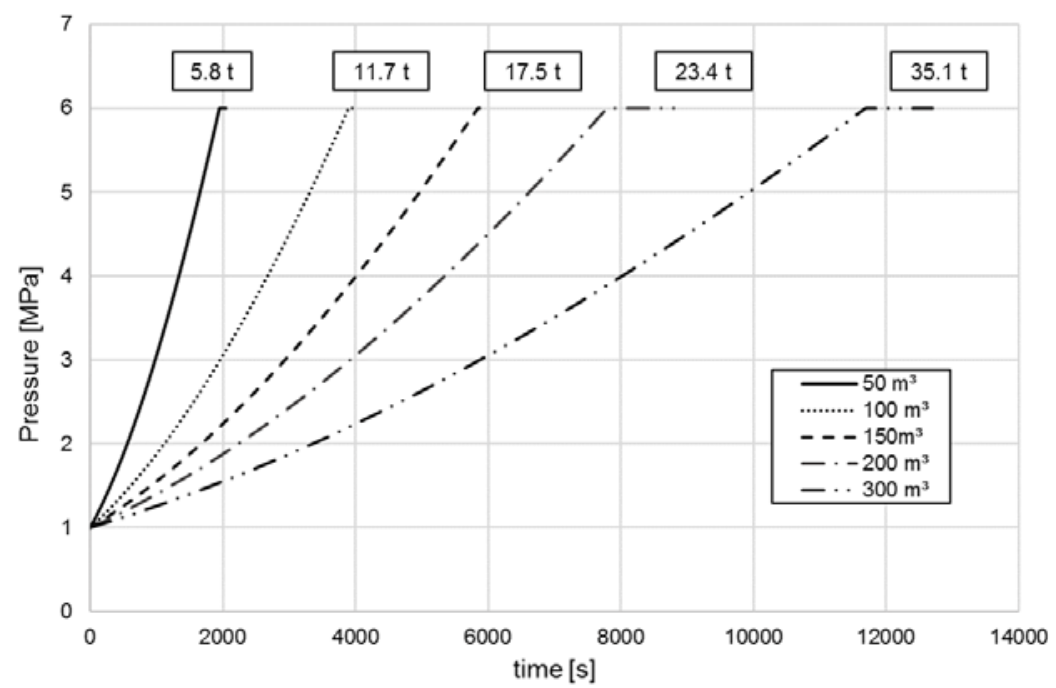

Figure 7: Charge of the steam accumulator.

Due to the constant live-steam properties and charge massflow, each storage size has the same thermal energy density $\omega\left(91.5 \mathrm{kWh}^{\star} \mathrm{m}^{-3}\right)$ and live-steam capacity $\left(116 \mathrm{~kg}^{*} \mathrm{~m}^{-3}\right)$. Therefore, the constant charge procedure leads to a proportional storage capacity for each SA. The energy density of the steam accumulator is calculated by the vessel volume and the energy of the charge steam $\left(\omega_{\text {th }}=Q_{\text {th }} / V_{S A}\right)$.

\subsection{Discharge operation:}

Figure 8 shows the discharge of a SA with a volume of $100 \mathrm{~m}^{3}$ (Fig 8a) and the respective electricity generation of the ST (Fig 8b) for three different turbine dimensions and mass flow rates. To determine the optimum turbine operation, the discharge mass flow is set as the design massflow $\dot{m}_{S T, m a x}$ of the respective turbine (Table 5). The mass flow remains constant over the whole discharge process. The pressure drop of the SA shows the typical sliding pressure discharge behaviour (figure 8a).Since the constant decreasing pressure results in a corresponding temperature and enthalpy reduction, the power generation of the ST decreases over time.
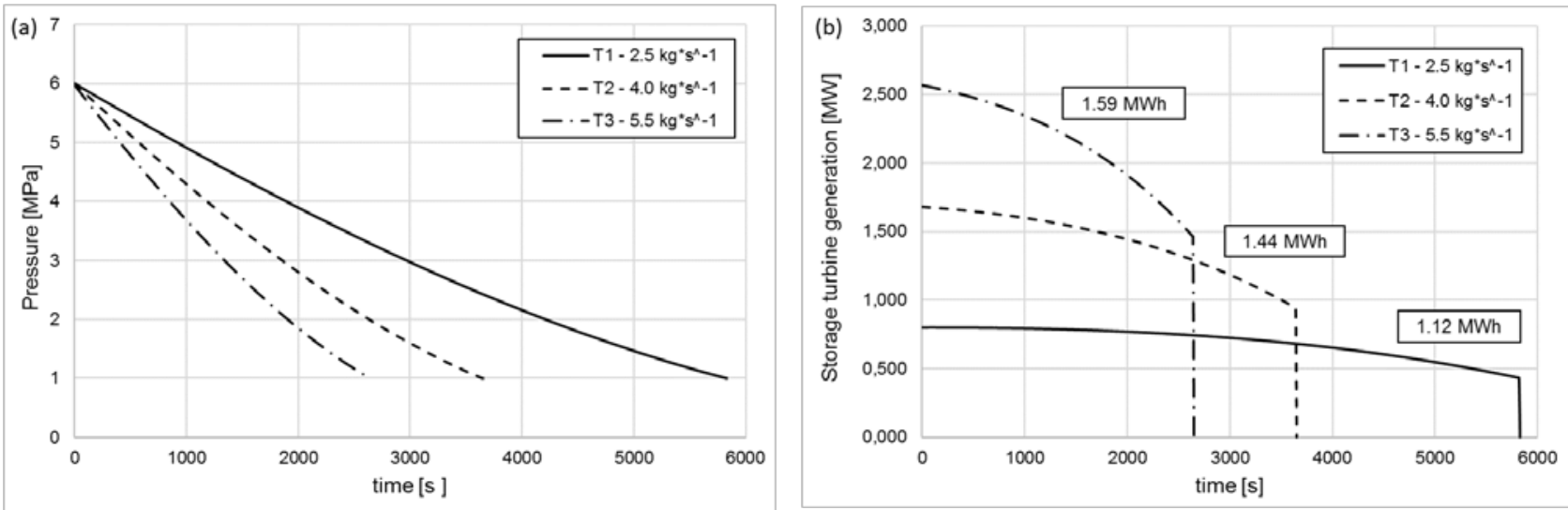

Figure 8: Discharge results. (a) Discharge of a SA with $V=100 \mathrm{~m}^{3}$ and (b) corresponding electricity generation of the ST. 
An unexpected result of the simulation study of the discharging process is represented by the significant differences of the produced electricity inbetween the different cases, despite the identical amount of discharged steam. While the totally generated electrical energy in case of a discharge mass flow of $\dot{m}_{\text {dis }}=\dot{m}_{2, \text { out }}=5.5 \mathrm{kgs}$ ${ }^{1}$ (T3) is about $1.59 \mathrm{MWh}$, the output of a discharge steam mass flow of $\dot{m}_{\text {dis }}=2.5 \mathrm{kgs}^{-1}$ is merely $1.12 \mathrm{MWh}$. The storage capacity of the SA in terms of electrical energy is therefore affected considerably by the discharge rate. While the equivalent capacity of the whole steam storage system is about $11.2 \mathrm{kWh}^{-3} \mathrm{~m}^{-3}$ in case of a massflow rate of $2.5 \mathrm{~kg}^{\star} \mathrm{s}^{-1}$, an increased flow rate of $5 \mathrm{~kg}^{\star} \mathrm{s}^{-1}$ results in a capacity of $15.9 \mathrm{kWh} \times \mathrm{m}^{-3}$. On the other hand, a lower massflow enables a longer discharge and is advantageous for flexible plant operation. The substantial differences are related to the efficiency of the ST $\eta_{\text {is, }}$ which mainly depends on the turbine size and the massflow rate $\dot{m}_{\text {dis. }}$ In conclusion, a high mass flow with a corresponding large turbine benefits the efficiency of the storage systems performance.

To identify the impact of the turbine dimension, an additional discharge simulation is performed. To allow a better comparison, the massflow rates 4.0 and $5.5 \mathrm{~kg}^{\star} \mathrm{S}^{-1}$ where simulated with both $\mathrm{T} 3$ and the origin turbine size from Figure 8.

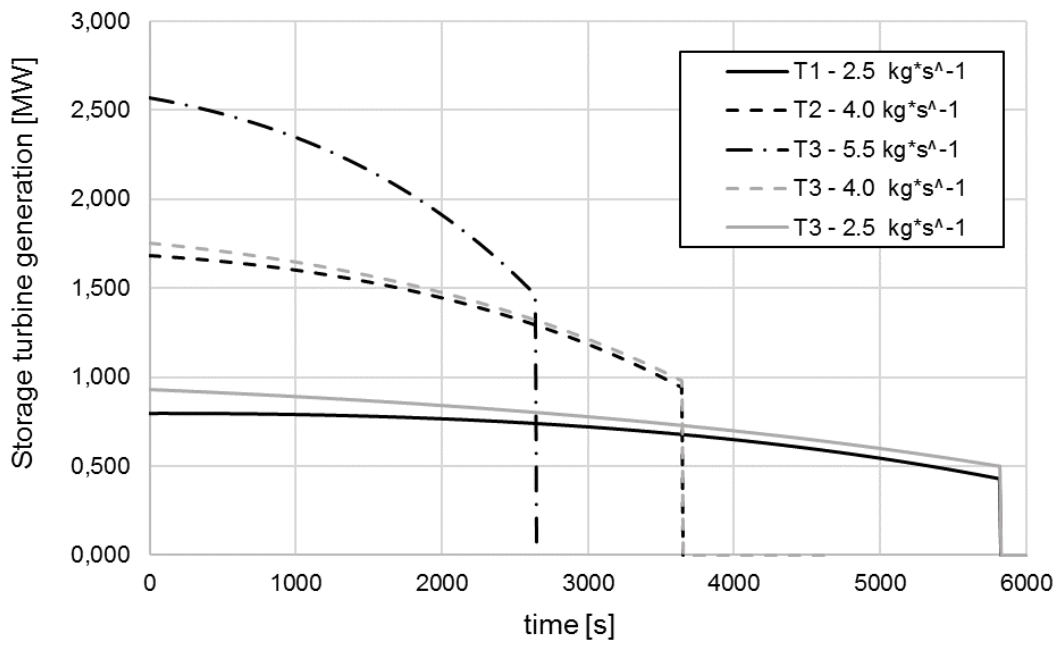

Figure 9: Discharge with different turbines sizes.

As shown in Figure 8, a higher power output is achieved with the larger turbine T3. It is important to note, that $\mathrm{T} 1$ and $\mathrm{T} 2$ are on the scale of the smallest commercially available turbines. Considering the electricity generation, a larger discharge turbine is beneficial. As further research, an economic minimum limit for the turbine dimension will be identified. With an identical discharge steam mass flow of $\dot{m}_{\text {dis }}=2.5 \mathrm{~kg}^{*} \mathrm{~s}^{-1}$, the total power generation of T3 $(1.24 \mathrm{MWh})$ is $11 \%$ higher than $\mathrm{T} 2(1.12 \mathrm{MWh})$. Utilizing a higher mass flow rate mis and a corresponding dimension of the ST, the total power generation can be increased significantly, even the amount of energy stored in the SA is equal in any cases. As shown in Figures 8 and 9 this effect is not only caused by the better design efficiency of the ST and has a significant impact on the results. In the discharge simulations of Figures 8 and 9, the total amount of steam, discharged from the SA, is equal in any case.

Generally Figures 8 and 9 show, that a part-load operation of the ST is possible although there will be efficiency losses, therefore, a variable discharge mass flow according to external grid or market demands is achievable. The short term markets which are aimed with this concept require power increase or decrease in a time range of a quarter up to a few hours. Therefore, the fundamental charge and discharge behaviour of the storage system is appropriate for this time scale. For market-driven operations the sliding pressure and thereby the decreasing power generation over time represents a main challenge. It is necessary to develop a control system for the charge/discharge valve, which allows to adjust the pressure drop in order to achieve a controllable and continuous power generation during discharge.

Furthermore, the initial simulations revealed, that the total mass of steam and condensed water inside the SA after a full charge and discharge cycle is lower compared to the initial state. In case of a SA with a volume of $100 \mathrm{~m}^{3}$, the total mass is reduced from $53.4 \mathrm{t}$ to $50.6 \mathrm{t}$ regardless of the mass flow rate. This is related to the fact, that the energy density of the superheated input steam is higher than the energy density of the saturated 
discharge steam. Hence, during an alternating charge and discharge operation, an additional external condensate massflow has to be supplied after the discharge process to balance the mass inside the storage and avoid mass decline, since the mass of the liquid phase inside of the SA represents a main impact factor for the thermal storage capacity, it is important too.

\subsection{Solid concrete thermal store}

Since a share of only $1-2 \%$ of the total thermal energy is stored in the CS, this component has no significant influence on the system from the energy perspective. Its main function is the necessary superheating of the discharge steam to prevent damage to the ST.

\subsection{Interaction with the Biomass Plant}

Considering the biomass CHP plant in combination with the steam storage system as a unit, the flexible performance can be calculated. The generated electricity during conventional baseload operation $Q_{B L}=P_{B L} X\left(t_{c h a}\right.$ $+t_{\text {dis }}$ ) and during flexible operation $Q_{\text {Flex }}=P_{\min } X t_{c h a}+P_{B L} x t_{d i s}+Q_{S T}$ is compared. The flexible efficiency $\eta_{\text {Flex }}$ is $\eta_{\text {Flex }}=Q_{F L E X} / Q_{B L}$. The maximum power $P_{\max }=P_{S T}+P_{B L}$ during discharging is changing over time, due to the sliding pressure of the SA. Another value to evaluate the performance of a flexible CHP plant, is the load range

$P_{L R}=P_{\max }-P_{\min }$. The results are presented in Table 6.

Table 6: Simulation results.

\begin{tabular}{|c|c|c|c|c|c|c|c|c|}
\hline Simulation case & units & symbol & 1 & 2 & 3 & 4 & 5 & 6 \\
\hline Simulation parameter & $\begin{array}{c}\mathrm{m}^{3} \\
\mathrm{~kg}^{*} \mathrm{~s}^{-1}\end{array}$ & $\begin{array}{c}\mathrm{V} \\
\dot{m}_{\text {dis }} \\
\text { turbine }\end{array}$ & $\begin{array}{l}100 \\
2.5 \\
\text { T1 }\end{array}$ & $\begin{array}{l}100 \\
4.0 \\
\mathrm{~T} 2\end{array}$ & $\begin{array}{l}100 \\
5.5 \\
\text { T3 }\end{array}$ & $\begin{array}{l}200 \\
2.5 \\
\text { T1 }\end{array}$ & $\begin{array}{l}200 \\
4.0 \\
\mathrm{~T} 2\end{array}$ & $\begin{array}{l}200 \\
5.5 \\
\text { T3 }\end{array}$ \\
\hline Charge time & $\mathrm{s}$ & $t_{\text {cha }}$ & 3,899 & 3,899 & 3,899 & 7,796 & 7,796 & 7,796 \\
\hline Discharge time & $\mathrm{s}$ & tdis & 5,840 & 3,660 & 2,660 & 11,670 & 7,300 & 5,310 \\
\hline Baseload generation & $\mathrm{MWh}$ & $\mathrm{Q}_{B L}$ & 16.15 & 12.53 & 10.87 & 32.27 & 25.03 & 21.73 \\
\hline ST generation & $\mathrm{MWh}$ & QST & 1.12 & 1.44 & 1.59 & 2.2 & 2.9 & 3.2 \\
\hline Flexible Generation & $\mathrm{MWh}$ & $Q_{\text {Flex }}$ & 13.46 & 10.17 & 8.66 & 26.90 & 20.31 & 17.31 \\
\hline Electricity loss & $\mathrm{MWh}$ & Qloss & 2.68 & 2.36 & 2.21 & 5.37 & 4.72 & 4.42 \\
\hline Flexible efficiency & - & $\eta_{\text {Flex }}$ & 0.83 & 0.81 & 0.79 & 0.83 & 0.81 & 0.79 \\
\hline Storage efficiency & - & $\eta$ & 0.30 & 0.38 & 0.42 & 0.38 & 0.50 & 0.58 \\
\hline Maximal capacity & $\mathrm{MW}$ & $P_{\max }$ & $6.8-6.4$ & $7.7-6.9$ & $8.5-7.4$ & $6.8-6.4$ & $7.7-6.9$ & $8.5-7.4$ \\
\hline Average load range & MW & $P_{L R}$ & 4.1 & 4.8 & 5.5 & 4.1 & 4.8 & 5.5 \\
\hline
\end{tabular}

The simulation shows that a flexible efficiency of around $80 \%$ and a load range next to the total capacity $P_{B L}$ of the CHP plant can be achieved. An increasing discharge mass flow results in higher value of $Q_{S T}, P_{\max }$ and $P_{L R}$. However the efficiency is decreasing in case of higher mass flows and a larger turbines. In this case study, the efficiency of the storage $\eta=Q_{\text {charge }} / Q_{\text {Discharge }}$ lies between $30-58 \%$. Additional simulation runs shows that utilizing a lower backpressure (5-10 kPa) in the ST can increase the storage efficiency up to $85 \%$.

\subsection{Role of the proposed concept in the field of energy storage technologies}

Among the available storage technologies to relief the electricity grid, very short term storage devices like super capacitors or flywheels are not considered for a comparative evaluation of the present approach, since 
the focus is set on the short-term markets. Comparing the proposed system with competing technologies (see Table 7$)$ the efficiencies as well as the energy density $\left(\omega_{\mathrm{el}}=\mathrm{Qst}_{\mathrm{s}} / \mathrm{V}\right)$ are located in the field of the range.

Table 7: Overview of different energy storage systems.

\begin{tabular}{|l|c|c|}
\hline & Efficiency & Electric energy density $\mathrm{kWh} / \mathrm{m}^{3}$ \\
\hline Proposed system & $30-85 \%$ & $10-50$ \\
\hline Pumped hydro storage (PHS) & $65-85 \%[19]$ & $0.5-1.5[20]$ \\
\hline Compressed air energy storage (CAES) & $54-88 \%[19]$ & $3-8[20]$ \\
\hline Li-lon batteries & $81-98 \%[19]$ & $200-250[21]$ \\
\hline Lead-Acid batteries & $63-90 \%[19]$ & $100[21]$ \\
\hline Hydrogen fuel cell & $20-35 \%[19]$ & $270-380[22]$ \\
\hline
\end{tabular}

Nowadays the preferred energy technology for grid relief is pumped hydro storage. Comparing the proposed concept with pumped storage technology shows that both a similar efficiency and a higher electrical energy density can be achieved by using a SA with a CS. In addition, the proposed system is applicable in a lower scale than PH or CAES systems. Hence, a decentralized application at existing biomass CHP plants is achievable. The single components of the proposed concept are established and advanced technologies, so this concept is likely to be cost effective. Especially the SA can also be utilized as a conventional thermal store for the improvement of the heat or steam supply to external costumers which enables additional benefits to the biomass CHP plant.

\section{Conclusion}

Including the steam accumulator concepts of Stevanovic et al. [15] and the modelling approach of Sun and Smith [17] to calculate the turbine performance, a Matlab/Simulink model of flexible biomass CHP plants is developed. The system consist of a steam accumulator (SA), a concrete thermal store (CS) and an additional storage turbine (ST). To understand the system behaviour, process parameters such as the SA volume (50 to $300 \mathrm{~m}^{3}$ ), discharge massflow (between 2.5 and $5.5 \mathrm{~kg} / \mathrm{s}$ ) and the storage turbine size (capacity between 0.8 and $2.6 \mathrm{MW}$ ) are varied to perform a sensitivity analysis. This paper reports an investigation of the interaction of the resulting energy storage system with a standardized biomass CHP plant.

The power generation of the storage turbine decreases during the discharge period. This has to be considered for the development of the discharge massflow controller. In addition, the discharge massflow rate has a significant influence on the electricity production. Although the total energy in the SA is equal in all the cases investigated, the total electricity production can be increased by up to $40 \%$ by using higher discharge massflow rates and larger steam turbine. This impact should be considered when designing and evaluating systems of this type.

Overall, it has been demonstrated that load shifts for several hours and a load range up to $93 \%$ of the total biomass CHP plant capacity can be achieved. This means that upgrading a biomass CHP plant with this type of thermal storage system can meet the demands of flexible power production described by Stark et al. $[5,7$, 13].

Comparing the performance of the proposed energy storage system with other available systems from a technical perspective, the proposed concept is promising. As this investigation has been carried out to identify the fundamental behavior only, a more detailed system investigation, especially of the behavior of the CS, will be necessary to form the basis of a comprehensive economic analysis. As none the technologies, utilized in this storage concept, are particularly advanced, risky or expensive a cost efficient system will be realistic.

Several tasks for further research work have been identified. It will be necessary to develop a more detailed model, implementing the solid thermal store and the charge/discharge valves. Since, the discharge mass flow has a significant impact on the systems efficiency and the storage performance, the start-up behaviour of the charging and discharging processes has to be considered. A control strategy has to be developed to counteract 
the sliding pressure discharge of the SA. Due to the decreasing pressure, temperature and enthalpy, the mass flow has to be increased to achieve constant power generation. In contrast to the model presented in this paper, the operation mode of the flexible plant has to be adapted to the available markets and local grid demands.

\section{Abbreviations}

2T Two-Tank Storage

3T Triple-Tank Storage

AHP Analytic Hierarchy Process

BPST Backpressure Steam Turbines

CAES Compressed Air Energy Storage

CHP Combined Heat and Power

CS Concrete Storage

DNL Distribution Network Level

DoF Degree of Fulfillment

PCM Phase Change Material

$\mathrm{PH} \quad$ pumped hydro storage

PL Lithium Salts Phase-Change Material

PK Potassium + Sodium Salts Phase-Change Material

SA Steam accumulator

ST Storage turbine

\section{Symbols}

h enthalpy

m;" steam mass flow

M mass

$\mathrm{n}$ slope of the Willans line

p pressure

P capacity

Q energy

$r \quad$ latent energy

$\mathrm{t}$ time

$\mathrm{T}$ temperature

$\mathrm{V} \quad$ volume

WINT intercept of the Willans line

$\vartheta$ spec. volume

$\omega \quad$ energy density

$\eta \quad$ efficiency 


\section{Superscripts}

saturated liquid

saturated steam

\section{Subscripts}

1 liquid

2 vaporous

FLEX flexible

BL baseload

LR load range

min minimal

max maximal

loss losses

in inlet

out outlet

B boundary

is isentropic

mech mechanical

dis discharge

cha charge

el electric

\section{Acknowledgment}

\section{References:}

[1] A. Castillo, D. F. Gayme, Grid-scale energy storage applications in renewable energy integration: A survey, Energy Conversion and Management 87 (2014) 885-894.

[2] A. Purkus, E. Gawel, N. Szarka, M. Lauer, V. Lenz, A. Ortwein, P. Tafarte, M. Eichhorn, D. Thrän Contributions of flexible power generation from biomass to a secure and cost-effective electricity supply-a review of potentials, incentives and obstacles in Germany, Energy, Sustainability and Society (2018) 8-18

[3] M. Dotzauer, D. Pfeiffer, M. Lauer, M. Pohl, E. Mauky, K. Bär, et al., How to measure flexibility - performance indicators for demand driven power generation from biogas plants, Renewable Energy 134 (2018) 135146

[4] E. Billig, D. Thraen, Renewable methan - A technology evaluation by multi-criteria decision making from a European perspective, Energy 139 (2017), 468-484

[5] M. Stark, M. Sonnleitner, W. Zoerner, R. Greenough, Approaches for Dispatchable Biomass Plants with Particular Focus on Steam Storage Devices, Chem. Eng. Technol. (40) (2017) 227-237

[6] S. Kuravi, J. Trahan, D.Y. Goswami ,M.M. Rahman, E. K. Stefanakos, Thermal energy storage technologies and systems for concentrating solar power plants, Progress in Energy and Combustion Science 39 (4) (2013) 285-319

[7] M. Stark, C. Trinkl, W. Zörner, R. Greenough, Methodological Evaluation of Storage Systems for Flexible Power Generation from Solid Biomass, Chem. Eng. Technol. 87 (10) (2018) 885-893 
[8] M. A. Gonzalez-Salazar, T. Kirsten, L. Prchlik Review of the operational flexibility and emissions of gas- and coal-fired power plants in a future with growing renewables, Renew. Sustain. Energy Rev. 82 (2018) 14971513

[9] M. Aneke, M. Wang. Energy storage technologies and real life applications - A state of the art review, Applied Energy 179 (2016) 350-377.

[10] M. Bdour, M. Al-Addous, M. Nelles, A. Ortwein, Determination of Optimized Parameters for the Flexible Operation of a Biomass-Fueled, Microscale Externally Fired Gas Turbine (EFGT) Energies 9 (2016) 856

[11] F. Nadeem, S. M. S. Hussain, P. K. Tiwari, A. K. Goswami, T. S. Ustun Comparative review of energy storage systems, their roles, and impact on future power systems. IEEEE Access 7 (2019) 85804574555 4585.

[12] F. Bao, C. Xu, Performance analysis of a two stage thermal energy storage system using concrete and steam accumulator, Applied Thermal Engineering (2011) 2764-2771

[13] G. Pahl, W. Beitz, Engineering Design, Springer, London, 3rd ed., London 2007

[14] W.-D. Steinmann, M. Eck, Buffer storage for direct steam generation, Solar Energy, 80 (10) (2006) 12771282

[15] V. D. Stevanovic, M. M. Petrovic, S. Milivojevic, B. Maslovaric, Prediction and Control of Steam Accumulation, Heat Transfer. Eng., 36(5) (2015) 498-510

[16] A. Biglia, L. Comba, E. Fabrizio, P. Gay, D. R. Aimonino, Steam batch thermal processes in unsteady state conditions, Applied Thermal Engineering, 118 (2017) 638-651

[17] L. Sun, R. Smith, Performance Modeling of New and Existing Steam Turbines, Ind. Eng. Chem. Res. 54 (6) (2015) 1908-1915

[18] M. Stark, M. Philipp, A. Saidi; W. Zörner, C. Trinkl, R. Greenough, Steam Accumulator Integration for Increasing Energy Utilisation of Solid Biomass-Fuelled CHP Plants in Industrial Applications, Chemical Engineering Transactions (2018) 2137-2143

[19] M. Baumann, M. Weil, J. F. Peters, N. Chibeles-Martins, A. B. Moniz, A review of multi-criteria decision making approaches for evaluating energy storage systems for grid applications, Renewable and Sustainable Energy Reviews 107 (2019) 516-534

[20] H. Mozayeni, X. Wang, M. Negnevitsky, Thermodynamic and exergy analysis of a combined pumped hydro and compressed air energy storage system, Sustainable Cities and Society 48 (2019) 1-11

[21] T. Wilberforce, Z. El-Hassan, F.N. Khatib, A. Al Makky. A. Baroutaji, J. G. Carton, A. G. Olabi. Developments of electric cars and fuel cell, International Journal of Hydrogen Energy (2017) 25695-25734

[22] C. E. Thomas, Fuel cell and battery electric vehicles compared, International Journal of Hydrogene Energy (2009) 6005-6020 